\title{
CMEARTICLE \\ Clinics in diagnostic imaging (149)
}

Nuttaya Pattamapaspong ${ }^{1}, \mathrm{MD}$, Malai $\underline{\text { Muttarak }}^{1}$, MD, Pruit Kitirattrakarn ${ }^{2}$, MD, Neelaya Sukhamwang ${ }^{3}$, MD
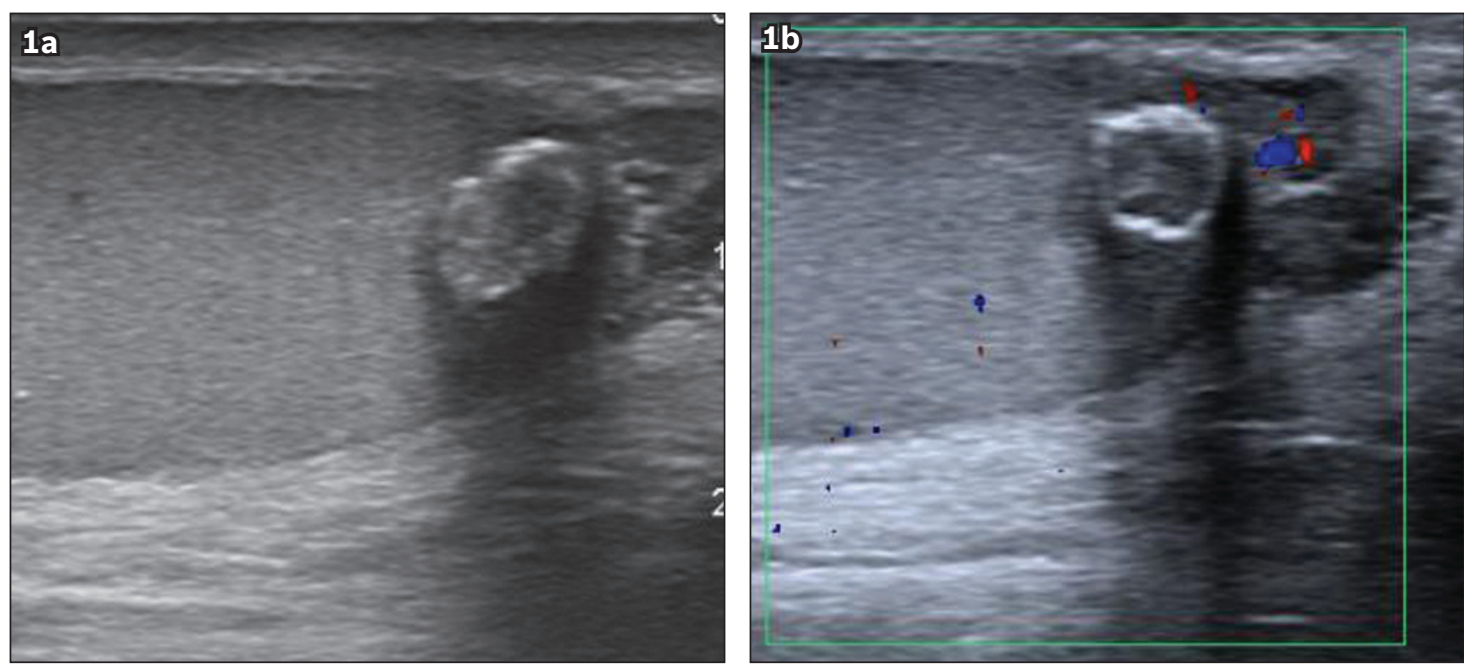

Fig. 1 (a) Longitudinal US and (b) colour Doppler US images of the right testis.
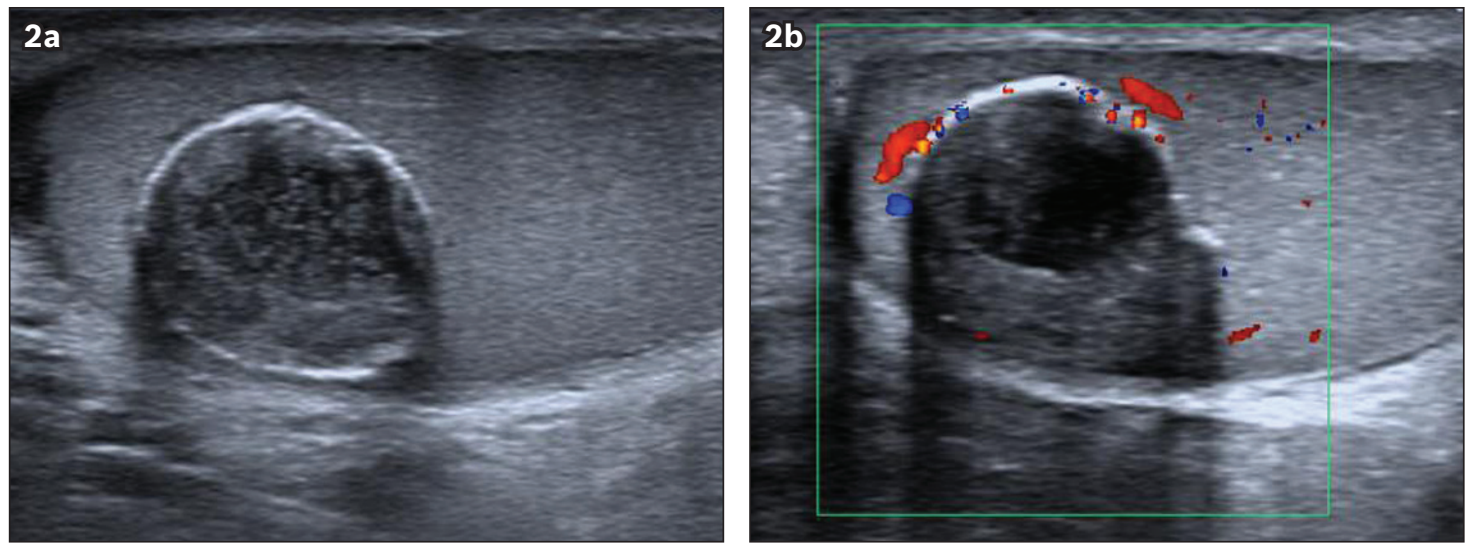

Fig. 2 (a) Longitudinal US and (b) colour Doppler US images of the left testis.

\section{CASE PRESENTATION}

A 33-year-old man presented with a painless, non-growing left testicular mass for five years. One month prior to admission, he felt vague discomfort in his left testicle. The patient had normal urination and no history of scrotal trauma. Physical examination revealed a healthy young man with normal blood pressure and no fever. There was no abnormality of the scrotal skin and both testes were of regular size. A non-tender, firm mass measuring about $2 \mathrm{~cm}$ was palpable in the left testis, but there was no palpable mass in the right testis. Routine blood tests, including complete blood count, electrolyte and urinalysis, were normal. Ultrasonography (US) of the scrotum was performed, and a provisional diagnosis of left testicular tumour was made. What do the US images of the scrotum (Figs. $1 \& 2$ ) show? What is the diagnosis?

${ }^{1}$ Department of Radiology, ${ }^{2}$ Department of Surgery, ${ }^{3}$ Department of Pathology, Chiang Mai University, Chiang Mai, Thailand

Correspondence: Prof Malai Muttarak, Professor, Department of Radiology, Chiang Mai University, 110 Intavaros Road, A Muang, Chiang Mai 50200, Thailand. malai.muttarak@gmail.com 


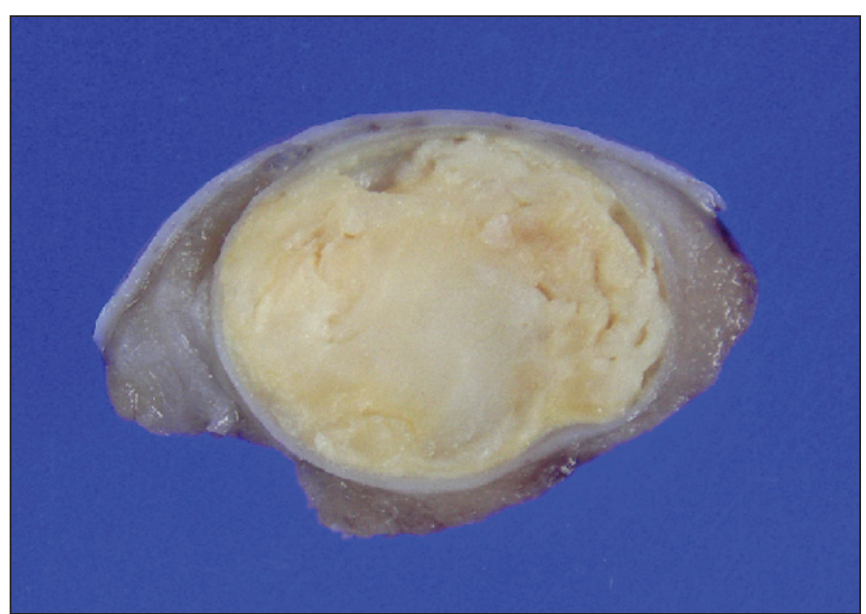

Fig. 3 Photograph shows the cut surface of a $1.5-\mathrm{cm}$, wellcircumscribed cystic mass from the left testis, which contains a white-yellow, paste-like material with a thick wall.

\section{IMAGE INTERPRETATION}

Longitudinal US image of the right testis (Fig. 1a) shows a lobulated, dense calcific mass with acoustic shadow in the lower pole of the testis. Colour Doppler US image (Fig. 1b) shows no vascular flow within the mass. Longitudinal US image of the left testis (Fig. 2a) shows a well-defined round mass with heterogeneous internal echo and a partially calcified wall. Colour Doppler US image (Fig. 2b) shows no vascular flow within the mass.

\section{DIAGNOSIS}

Bilateral testicular epidermoid cysts.

\section{CLINICAL COURSE}

The patient underwent wedge resection of both testicular masses. His postoperative course was uneventful. Pathology of the masses revealed epidermoid cysts (Figs. 3 \& 4) with normal surrounding testicular tissue. He was well at the six-month follow-up.

\section{DISCUSSION}

Epidermoid cysts, also known as keratocysts, are rare benign tumours of the testis, accounting for $1 \%-2 \%$ of all testicular neoplasms. ${ }^{(1,2)}$ Bilateral testicular epidermoid cysts are even rarer, and to our knowledge, only 15 patients have been reported in the English literature. ${ }^{(3-6)}$ Multiple cysts have been reported in patients with Gardner syndrome, Klinefelter syndrome and cryptorchid testes. ${ }^{(7,8)}$ The age of affected patients range from 3 to 77 years, with the majority in the second to fourth decades of life. Clinically, most patients are asymptomatic, with testicular mass incidentally discovered during self-examination or routine physical examination. Occasionally, patients may present with scrotal pain, enlargement or vague discomfort - symptoms similar to those of malignant testicular tumours. ${ }^{(2,7,8)}$

US is an accurate imaging modality in the detection of testicular masses and differentiation of solid from cystic
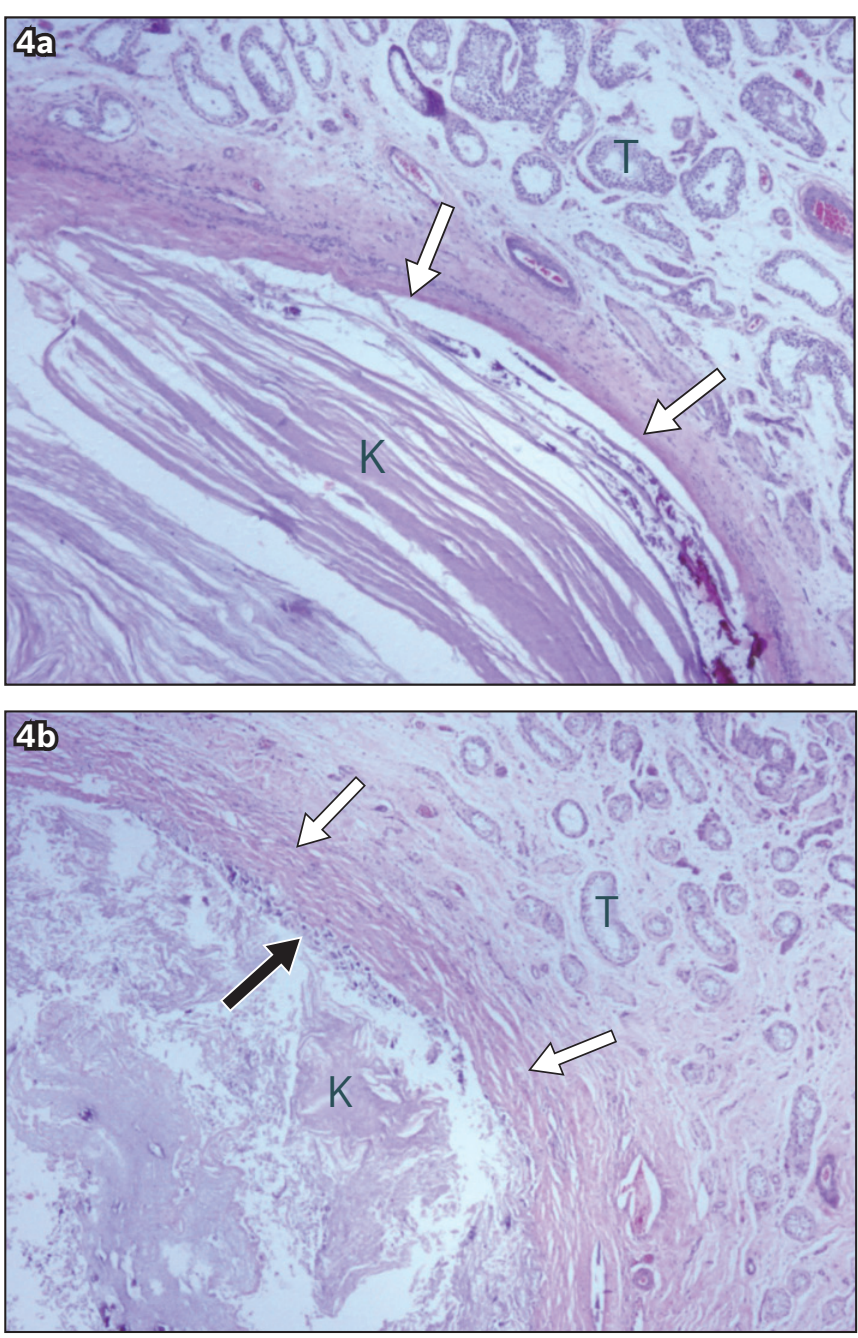

Fig. 4 Photomicrographs of the (a) right and (b) left epidermoid cysts show a dense fibrous wall (white arrows) with calcifications (black arrow) and keratin content (K). The adjacent seminiferous tubules ( $T$ ) are normal. (Haematoxylin \& eosin, × 100)

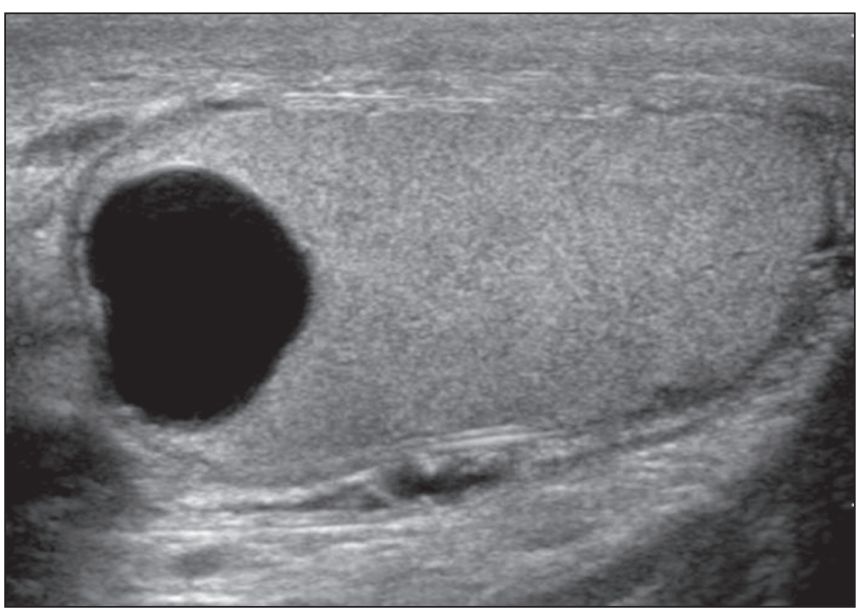

Fig. 5 Longitudinal US image shows a well-circumscribed anechoic mass.

masses. ${ }^{(9)}$ An epidermoid cyst is often seen as a wellcircumscribed mass with a hyperechoic rim, corresponding to the histopathologic finding of a dense fibrous wall. The presence of acoustic shadow in the wall indicates calcification. Although histologically defined as cysts, epidermoid cysts are different from other intratesticular cysts, which are completely 

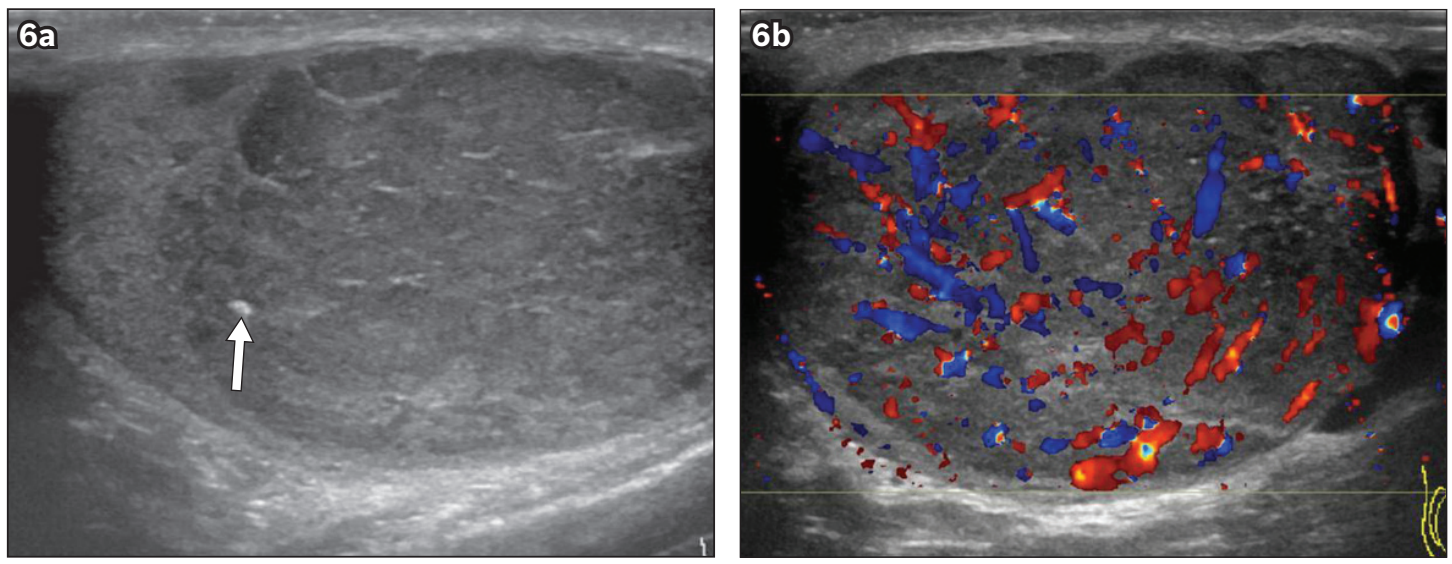

Fig. 6 (a) Longitudinal US image shows an enlarged testis with heterogeneous echo and an ill-defined hypoechoic mass with calcification (arrow). (b) Colour Doppler US image shows increased vascularity within the mass.
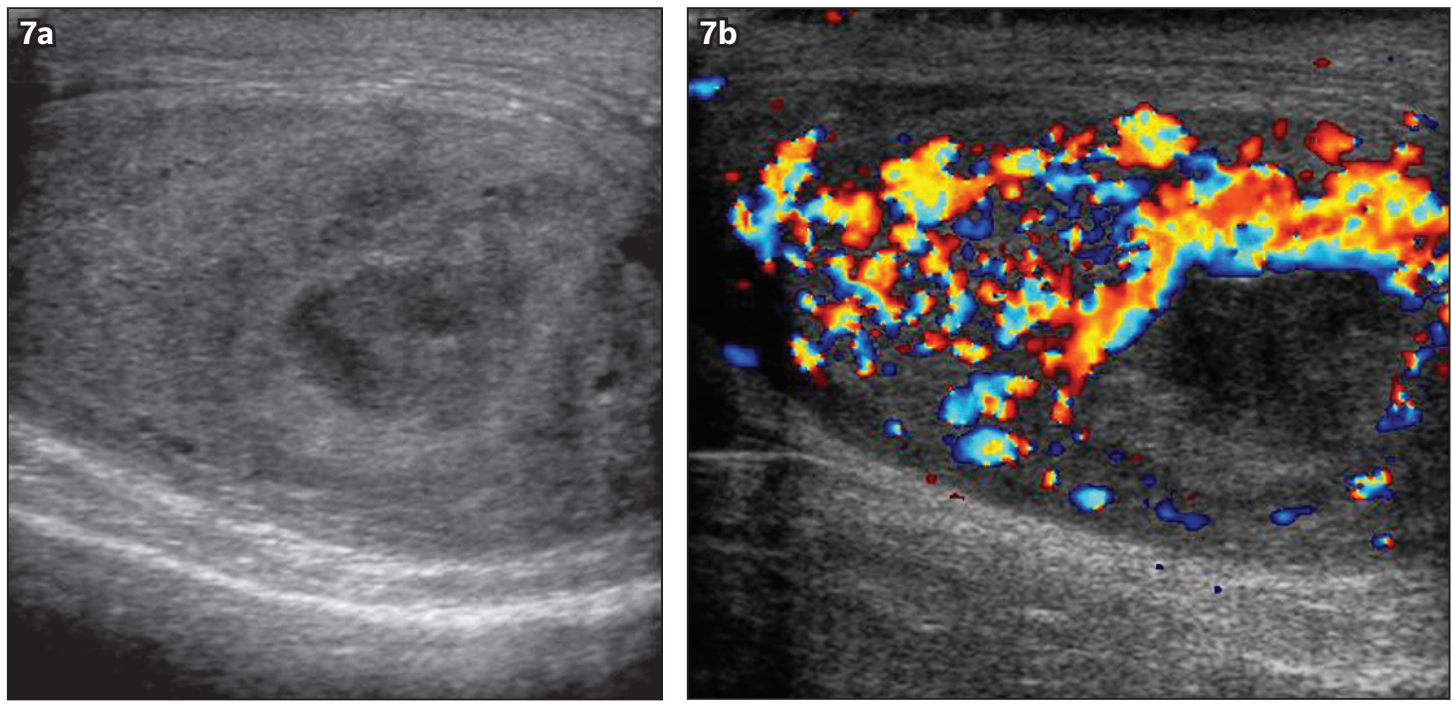

Fig. 7 (a) Longitudinal US image shows an ill-defined heterogeneous hypoechoic mass with cystic component. (b) Colour Doppler US image shows markedly increased vascularity in the surrounding testicular parenchyma.

anechoic (Fig. 5). Epidermoid cysts show variable echogenicity, from a heterogeneous hypoechoic mass to dense hyperechoic mass with acoustic shadowing on US, depending on the maturation, compactness and quantity of keratin content. On colour Doppler US, the cyst shows absence of blood flow. The reported characteristic features of epidermoid cysts are alternating hypo- and hyperechoic concentric rings (an 'onion ring' appearance), and an echoic centre surrounded by hypoechoic concentric rings (a 'target' or 'bull's eye' appearance); however, these appearances are not pathognomonic. ${ }^{(2,3,7,9-13)}$ Malignant testicular tumours, abscesses and teratomas can produce similar US appearances. A mass with ill-defined or irregular borders and increased vascularity within the mass raises the suspicion of malignancy (Fig. 6). ${ }^{(9,13)}$ Testicular abscesses usually have ill-defined borders and increased vascularity in the surrounding testicular parenchyma (Fig. 7). Teratomas are tumours that comprise three germ cell layers. Complex echotexture in teratomas reflects tissue component and may be indistinguishable from epidermoid cysts. Therefore, care must be taken to differentiate between teratomas and benign epidermoid cysts. When US findings are equivocal, magnetic resonance (MR) imaging may have a role in the evaluation of testicular masses. ${ }^{(14)}$ On MR imaging, epidermoid cysts may have an 'onion ring' or 'target' appearance similar to that on US, with the absence of contrast

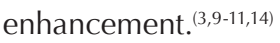

The histogenesis of epidermoid cysts is unclear. Most authors have suggested that an epidermoid cyst represents monodermal development of a teratoma, while some opined that it points to metaplasia of the rete testis or seminiferous epithelium..$^{(8,12,15)}$ Price $^{(16)}$ defined the pathological criteria for diagnosis of testicular epidermoid cyst as follows: (a) the cyst must be in the testicular parenchyma; (b) the cyst wall is composed of fibrous tissue with a complete or incomplete inner lining of squamous epithelium; (c) the cyst lumen contains keratin debris; (d) teratomatous components such as sebaceous glands or hair follicles are absent; and (e) scar tissue is absent in the remaining testicular parenchyma. The presence of teratomatous components is a pathologic pattern of dermoid cysts or teratoma, and scar tissue in the testicular parenchyma may signify a burnt-out malignant germ cell tumour. Our presented case met the aforementioned pathological criteria. 
The optimal treatment of epidermoid cysts remains debatable. Previously, most surgeons favoured inguinal orchiectomy due to the fact that malignant masses of the testis are far more common than epidermoid cysts and preoperative diagnosis is usually insufficient to exclude malignancy. Recent studies, however, support treatment with testis-sparing surgery in order to preserve fertility without the increased risk of tumour recurrence. Preoperative US is the recommended imaging modality for diagnosis and localisation of the tumour. US findings of a well-circumscribed mass with a hyperechoic or calcified wall and an 'onion ring' or 'target' appearance, accompanied by the absence of vascular flow on colour Doppler US, should direct the radiologist to diagnose this benign lesion. In the present case, although the patient's tumour did not show a characteristic 'onion ring' or 'target' appearance, in the setting of a non-growing mass for five years with bilateral well-circumscribed calcific masses, which is also suggestive of epidermoid cysts, orchiectomy could be avoided. As most solid intratesticular masses are malignant, some surgeons recommend performing testis-sparing surgery if (a) frozen sections confirm the diagnosis of epidermoid cysts, (b) two biopsies of surrounding testicular parenchyma show no associated malignancy in patients with tumours $<3 \mathrm{~cm}$, and (c) tumour markers ( $\alpha$-fetoprotein and $\beta$-human chorionic gonadotropin) are negative. ${ }^{(7,17)}$ Currently, long-term follow-up in patients with epidermoid cysts treated with testis-sparing surgery has not showed any subsequent recurrence. ${ }^{(3,4,6,13,17)}$

ABSTRACT A 33-year-old man presented with a painless, non-growing left testicular mass for five years. Preoperative ultrasonography (US) of the scrotum showed a small, circumscribed calcific mass in the right testis and another well-defined heterogeneous echoic mass with a partially calcified wall in the left testis, with avascularity on colour Doppler US. These imaging findings in a clinical setting of non-growing testicular masses were highly suggestive of epidermoid cysts, thus leading to testis sparing surgery. Histopathology confirmed bilateral epidermoid cysts. To the best of our knowledge, only 15 cases of bilateral epidermoid cysts have been reported. We discuss the US features of epidermoid cyst and its surgical management, as well as various cases of testicular masses.

Keywords: epidermoid cyst, testicular neoplasms, testis-sparing surgery, ultrasonography

\section{REFERENCES}

1. Dieckmann KP, Loy V. Epidermoid cyst of the testis: a review of clinical and histogenetic considerations. Br J Urol 1994; 73:436-41.

2. Moghe PK, Brady AP. Ultrasound of testicular epidermoid cysts. Br J Radiol 1999; 72:942-5.

3. Cittadini G, Gauglio C, Pretolesi F, Santacroce E, Derchi LE. Bilateral epidermoid cysts of the testis: sonographic and MRI findings. J Clin Ultrasound 2004; 32:370-2.

4. Khalid M, Malik N, Salauddin MA, Rashid M. Concomitant bilateral testicular epidermoid cysts. Saudi Med J 2008 ;29:907-9.

5. Loberant N, Bhatt S, Messing E, Dogra VS. Bilateral testicular epidermoid cysts. J Clin Imaging Sci 2011; 1:4.

6. Su CM, Lee YL, Huang SP, Chou YH, Huang $\mathrm{CH}$. Testicular sparing surgery for bilateral epidermoid cysts of the testes: a case report. Kaohsiung J Med Sci 2004; 20:83-5.

7. Loya AG, Said JW, Grant EG. Epidermoid cyst of the testis: radiologicpathologic correlation. Radiographics 2004; 24 Suppl 1:S243-6.

8. Shah KH, Maxted WC, Chun B. Epidermoid cysts of the testis: a report of three cases and an analysis of 141 cases from the world literature. Cancer 1981; 47:577-82.

9. Woodward PJ, Sohaey R, O'Donoghue MJ, Green DE. From the archives of the AFIP: tumors and tumorlike lesions of the testis: radiologic-pathologic correlation. Radiographics 2002; 22:189-216.

10. Cho JH, Chang JC, Park BH, Lee JG, Son CH. Sonographic and MR imaging findings of testicular epidermoid cysts. AJR Am J Roentgenol 2002; 178:743-8.

11. Dogra VS, Gottlieb RH, Rubens DJ, Liao L. Benign intratesticular cystic lesions: US features. Radiographics 2001; 21 Spec No:S273-81.

12. Dogra VS, Gottlieb RH, Rubens DJ, Oka M, Di Sant Agnese AP. Testicular epidermoid cysts: sonographic features with histopathologic correlation. J Clin Ultrasound 2001; 29:192-6.

13. Maizlin ZV, Belenky A, Baniel J, et al. Epidermoid cyst and teratoma of the testis: sonographic and histologic similarities. J Ultrasound Med 2005; 24:1403-9; quiz 1410-1.

14. Kim W, Rosen MA, Langer JE, et al. US MR imaging correlation in pathologic conditions of the scrotum. Radiographics 2007; 27:1239-53.

15. Weitzner S. Epidermoid cyst of testis: report of five cases and review of the literature. J Urol 1964; 91:380-6.

16. Price EB Jr. Epidermoid cysts of the testis: a clinical and pathologic analysis of 69 cases from the testicular tumor registry. J Urol 1969; 102:708-13.

17. Heidenreich A, Engelmann UH, Vietsch HV, Derschum W. Organ preserving surgery in testicular epidermoid cysts. J Urol 1995; 153:1147-50. 


\section{SINGAPORE MEDICAL COUNCIL CATEGORY 3B CME PROGRAMME} (Code SMJ 201311B)

Question 1. Concerning clinical presentation of patients with testicular epidermoid cysts:

(a) Most are over 50 years of age.

(b) Most are asymptomatic.

(c) Bilateral lesions are common.

(d) It cannot be differentiated from malignant testicular tumours through physical examination.

Question 2. Ultrasonographic features of an epidermoid cyst include:

(a) An anechoic cyst.

(b) A mass with alternating hypo- and hyperechoic concentric rings.

(c) A mass with an echoic centre surrounded by hypoechoic concentric rings.

(d) A hypervascular mass.

Question 3. Ultrasonographic features of epidermoid cysts must be differentiated from those of:
(a) Germ cell tumours.
(b) Abscesses.
(c) Dilated rete testes.
(d) Teratomas.

Question 4. The pathological criteria for diagnosis of epidermoid cysts include:
(a) The cyst must be in the testicular parenchyma.
(b) The cyst lumen contains keratin debris.
(c) Scar tissue is present in the testicular parenchyma.
(d) Teratomatous components are absent.

Question 5. Concerning the treatment of epidermoid cyst, testicular sparing surgery is recommended when:
(a) The mass is less than $5 \mathrm{~cm}$.
(b) Two biopsies of the surrounding testicular tissue are negative for malignancy.
(c) Frozen sections confirm the diagnosis of an epidermoid cyst.
(d) Tumour markers are negative.

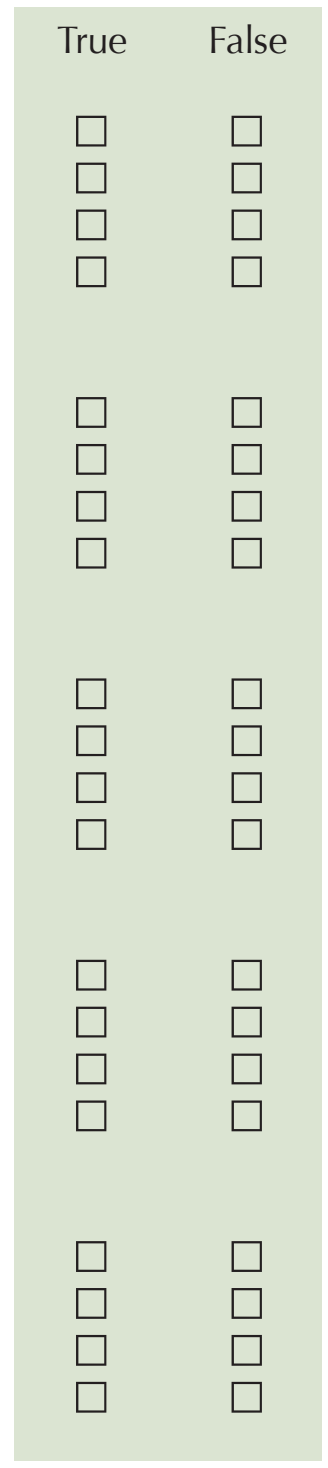

\footnotetext{
Doctor's particulars:

Name in full

MCR number

Email address

Specialty:

(1) Log on at the SMJ website: http://www.sma.org.sg/publications/smjcurrentissue.aspx and select the appropriate set of questions. (2) Provide your name, email address and MCR number. (3) Select your answers and click "Submit".

RESULTS:

(1) Answers will be published in the SMJ January 2014 issue. (2) The MCR numbers of successful candidates will be posted online at the SMJ website by 23 December 2013. (3) Passing mark is $60 \%$. No mark will be deducted for incorrect answers. (4) The SMJ editorial office will submit the list of successful candidates to the Singapore Medical Council. (5) One CME point is awarded for successful candidates.

Deadline for submission: (November 2013 SMJ 3B CME programme): 12 noon, 16 December 2013.
} 